\title{
PHOTOGRAMMETRY POSSIBILITIES AND RULES FOCUSING ON ARCHITECTURAL USAGE
}

\author{
${ }^{1}$ Olivér RÁK ${ }^{*}{ }^{2}$ Dorottya SZILÁGYI \\ ${ }^{1}$ Breuer Marcel Doctoral School, Department of Engineering Studies \\ Institute of Smart Technology and Engineering, Faculty of Engineering and Information \\ Technology, Boszorkány u. 2 and János Szentágothai Research Center, Ifjúság u. 20 \\ University of Pécs, H-7624 Pécs, Hungary, e-mail: rakoliver90@gmail.com \\ ${ }^{2}$ Architectural Engineer (BSc), Faculty of Engineering and Information Technology \\ Boszorkány u. 2, University of Pecs, H-7624 Pécs, Hungary, e-mail: szdo95@gmail.com
}

Received 23 April 2019; accepted 1 July 2019

\begin{abstract}
The article is presenting a consideration of the photogrammetry technology in the field of architectural usage. The technology overview is describing a basic knowledge to support the professionals. The processes, rules and best practices are examined through case studies, which introduce a dwelling house, an old precast concrete hall and a landscape surveying to cover most of the architectural usage. The purpose of the research is to give guidance for technical possibilities and assists in the development of the methodologies. The main part of the article is focusing on unmanned aerial vehicles as these tools provide many useful features.
\end{abstract}

Keywords: Building survey, Photogrammetry, Point cloud, Spatial data, Unmanned aerial vehicle

\section{Introduction}

The development of the photo resolution and the ease of using the cameras induced to utilize the images for surveying and as a reference data for the $3 \mathrm{D}$ modeling process. The status of information technology allows making a lot of calculations very fast with computer-supported methods. The general workflow of the photogrammetry is to detect the same points or pixels on the pictures. The different positions of the captured images can be calculated by software or by the surveying tools to determine the threedimensional coordinates of the points. The new technology can be cheaper than Terrestrial Laser Scanning (TLS) [1] or Airborne Laser Scanning (ALS) [2], which

\footnotetext{
${ }^{*}$ Corresponding Author
} 
means a big potential on the market. The technology was first used for landscape surveying where a lot of scientific and practical research is available [3]-[8]. Nowadays the architectural usage is becoming a more focused area, but the methodology is not clarified well. This is why the research is relevant to give an overview for the professionals.

Definition: the photogrammetry is a technology and science, which is extracting the three-dimensional geometrical information about and object or scene from images and range data [9]. It clearly determines how the technology is working but the processes need a more detailed explanation.

\section{Methodology and process overview}

The traditional surveying methods are useful in the field of architectural measuring but the professionals are looking for new digitalized and more effective methods. One of these can be the photogrammetry where the final results are point cloud, mesh-, tiled model or any different kind of views (e.g. orthophoto).

The technology needs only basic devices like a hand-held camera (a phone can be used also) or an Unmanned Aerial Vehicle (UAV) with a high-resolution camera. The methodology is very simple; the surveying person has to take pictures of the object or the building from different standing positions. After gathering the information, the images can be imported into specific photogrammetry software, which will calculate the spatial $(X, Y, Z)$ coordinates of the points.

In this study, the software calculation processes [10]-[12] are not explained, because the purpose was to give an overview and guidance for the architects about the photogrammetric survey process in general. Fig. 1 represents the general theoretical process visualization. After the Photo 1 and Photo 2 are taken, then if the positions of the pictures are correct, the same detected point's coordinates can be calculated by the software. 2 lines intersections are defining the positions of P1 and P2, which have spatial coordinates; in general more pictures are used to have more accurate results. The process is usually called photo alignment (detection method) and spare point cloud generation (calculation method) in the software.

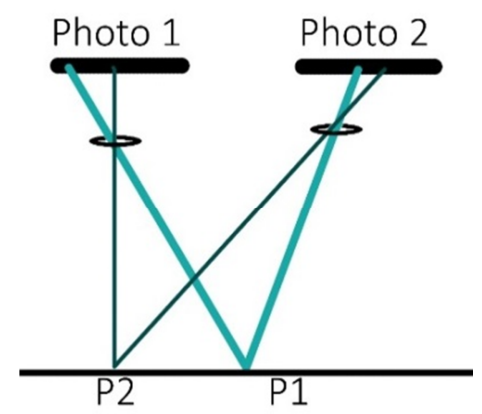

Fig. 1. General theoretical figure about the software calculation methodology (Source: Olivér Rák) 


\subsection{Photo capturing rules}

This chapter is providing information and guidance for the data capturing processes. It is explaining general information about the rules, which are necessary to know before starting a photogrammetry survey.

In the written user manuals [13], [14] of the different platforms are determined that the recommended image capturing position depends on the shape of the space or the form of the measured elements. In general, the perpendicular position to the surface will give the best results during the calculation process. If an object (e.g. statue) will be surveyed, then the photos should be taken all around in different height. A wide range of lens can be used (e.g. normal, fish eye lens) but this information has to be added into the software settings.

The Global Positioning System (GPS) information can be added to the images (as Geo-tag) during the capturing process but the possibilities are depending on the device features. The software algorithms can give better results according to the saved 3D spatial position of the picture but it is not necessary to have. Some tools are capable of capturing the position of the device and the camera angle also. External or built-in GPS tracker can be used also.

Because of the tie point detection methods, the captured images need to have overlapping areas. $60-80 \%$ is suggested by most of the user manuals. If this value is less than $60 \%$, the calculation process can fail because the software will not find relevant points. The overlapping can be managed in a manual or an automatic way at the survey.

The use of UAV has a lot of advantages. The photo shooting method can be automated, which makes it possible to have exact (application calculated) overlapping between images. Much human work is not needed during the surveying process, because only the rules need to be specified. In the case of normal (hand-held) cameras, it can be a problem to reach the higher parts of the buildings. As it was discussed in point 2.1., the perpendicular position is the best for the surveying but from the ground, it is impossible to perform, in this situation a UAV can offer the solution. The device can fly up to the covered parts and take pictures from the 'best' position. The UAVs usually have GPS positioning system, which is capturing the geo-tag during the measuring process.

The landscape survey case study is introducing an automatic flight possibility. Resolution of the captured images has a huge effect on the results also. It is evident; if the picture is built up from more pixels $/ \mathrm{cm}$ then more reference points are available for the detection. The accuracy and the dense of the point clouds are mainly influenced by the software settings and photo resolution.

\subsection{Processes before or after the on-site works}

The surveying should start with the planning of the methods and flight routes. The data storage is also a crucial issue. The post-production is necessary to be managed in the correct way after the surveying process.

The survey plan should be described first because the data needs to be captured in a structured system to have good final results. Planning the flight route and the required time is necessary before the start of the process, as in general, the capacity of the 
batteries makes it possible to fly about 30 minutes with one charge. The measured size of the surface or the object has an effect on the planned route and the reference target positions. The targets can be placed before the photos are taken and can be used as reference points during the survey. The printed targets are coded to be usable and automatically detectable by the software [15].

Safety planning is also a crucial part of the UAV flying. The UAVs are objects in the air, which are operating with precision software, but it can have errors in a reason of weather, sensor problems, etc. During the flight, the safety regulation is the main thing to be carried out.

The flight regulation in Hungary is very difficult, it is under development. Nowadays before flying liability insurance, flight permission, a safety survey, air navigation service permission is needed to have. All the rules are clearly defined on the website of Legter.hu [16].

The After Process (AP) has a huge effect on the final results. Those are the captured data software processing solutions and finding the correct settings to reach the expected spatial data accuracy. Nevertheless, as it was mentioned in point 2, this field of surveying is not in focus of the research.

\section{Case studies}

During the case studies a DJI Phantom 4 UAV and Apple Ipad 6 controller devices were used. (Specifications are described as references: [17], [18].) The used applications were different but those are mentioned in the following chapters.

\subsection{Family house facade surveying}

Application: DJI GO 4, Surveying tool: DJI Phantom 4, AP software: Agisoft PhotoScan.

The building location is a small town in Hungary. The environment is clear but a busy road is next to it. This is the reason why only half of the building was measured because flying above the street is dangerous. The accuracy of the survey was near to perfect, it was verified by traditional survey tools. The texture of the facade helps to detect reference points for the software calculation. Fig. 2 represents the surveyed building shape in a point cloud format. During the research 89 pictures were taken in 15 minutes and the AP time was 2.5 hours.

\subsection{Row house facade surveying}

Application: DJI GO 4, Surveying tool: DJI Phantom 4, AP software: Agisoft PhotoScan.

The building environment is very crowded. Near to the facade, there is a tree, which makes the process difficult. In this case, the sensors were unable to use because all the obstacles were too close and the UAV could not move forward. The first step was to change the settings in the application and switch off the sensors. The measuring process took only 10 minutes. There was another idea tested to record a video and export the 
pictures from it. The difference between these two methodologies is that from the video 30 frames per second can be exported compared to the photo shooting, which is maximum one picture in every 2 seconds. The video exported pictures have no GPS data and some of those are unusable, which comes from the missing focus issue. As it is shown in Fig. 3 and Fig. 4 the difference is not significant in the results so all the techniques can be used depending on which is easier and faster to make. It has to be stated in case of video recording, the camera and the UAV have to move slowly to have better focus.

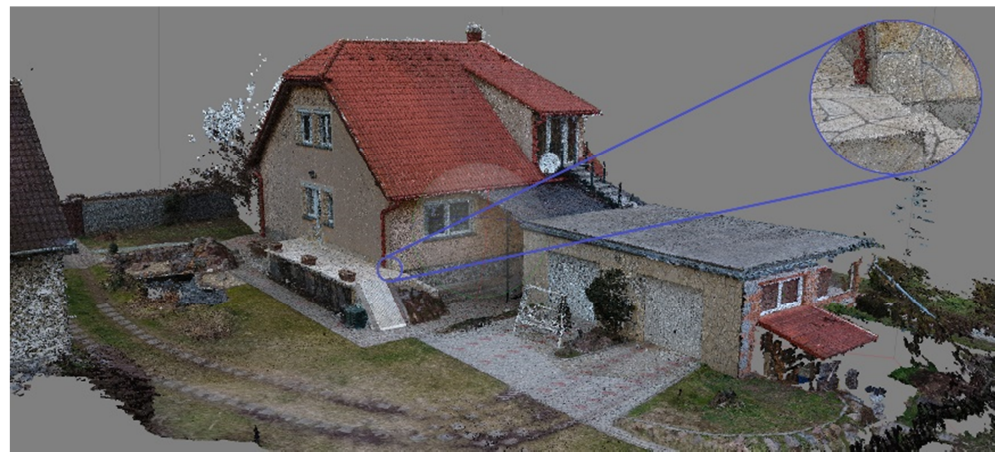

Fig. 2. Generated point cloud by Agisoft PhotoScan (Source: Olivér Rák)

\subsection{Old market hall interior and exterior surveying}

Application: DJI GO 4, Surveying tool: DJI Phantom 4, AP software: 3DF Zephyr.

This was the first flight with the UAV interior because it needs to have confident practice in the controlling. The space was limited, filled with obstacles, missing GPS sign, application warnings, lack of light and dust in the area. The same rules have been used as it was mentioned in point 2.1. As it is shown in Fig. 5 the walls were painted by graffiti artists, which helped during the AP because the software found a lot of reference points on the pictures.

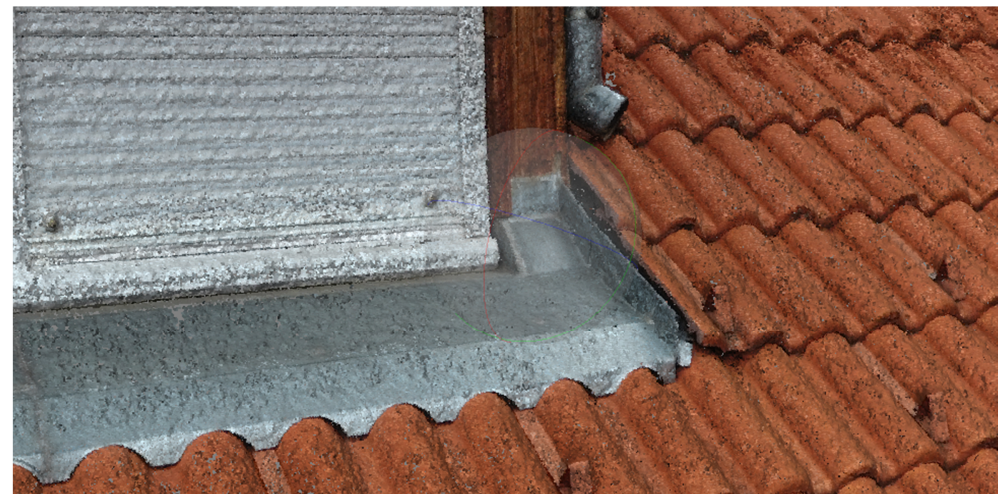

Fig. 3. Point cloud detail of the surveyed roof from images with geo-tag (Source: Olivér Rák) 


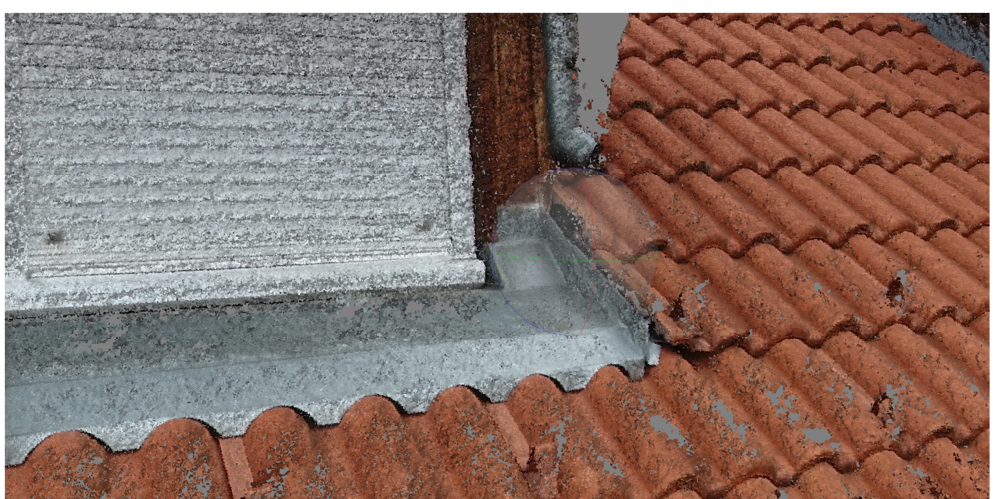

Fig. 4. Point cloud detail of the surveyed roof from video exported images (Source: Olivér Rák)

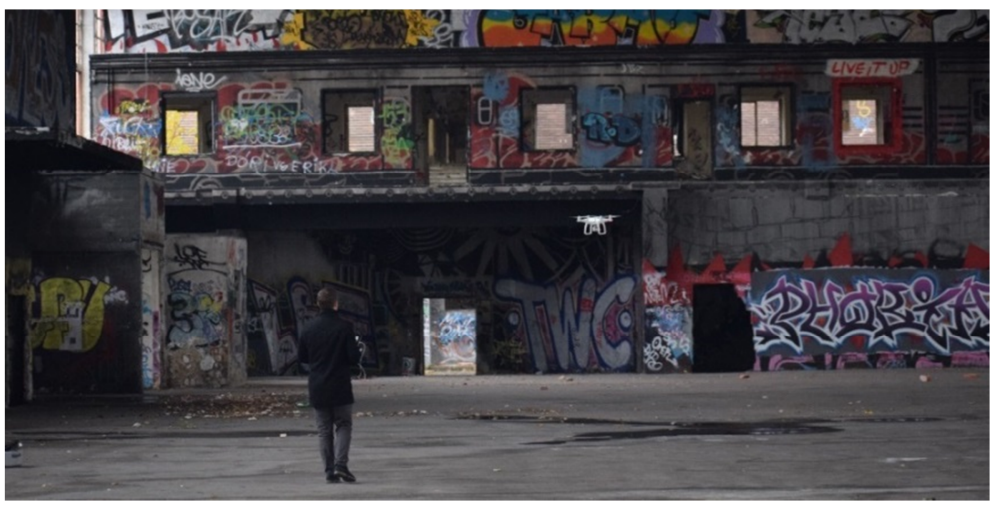

Fig. 5. Interior flight with UAV to survey the face of the walls (Source: Olivér Rák)

At the exterior, the size of the building means issues because it needs to have more batteries to survey the whole facade. It was a research project so the decision was made to measure only the $1 / 3$ part of the $\sim 220 \mathrm{~m}$ length prefabricated concrete building. The process takes 3 hours at the interior and exterior side. There were 725 pictures taken and more than 10 million points were generated from those. Fig. 6 represents the point cloud with the UAV camera positions in the 3D.

\subsection{Landscape surveying}

Application: Litchi for DJI Drones, Surveying tool: DJI Phantom 4, AP software: Agisoft PhotoScan.

The research idea comes from a need of the University of Pécs to have exact terrain model for the building design course exercise. The landscape was huge with existing industrial buildings and vegetation. The same UAV was used for this research also, to get comparable results. The Litchi application was tested, which has a route planning feature. It was important to have a precise overlap between the images and with this, the planning process was easy to make. For that, only the flight altitude $(100 \mathrm{~m})$ and the 
area need to be defined on a map. The application calculated the position where the photo would be taken to have the $80 \%$ of overlap, as it is shown in Fig. 7 .

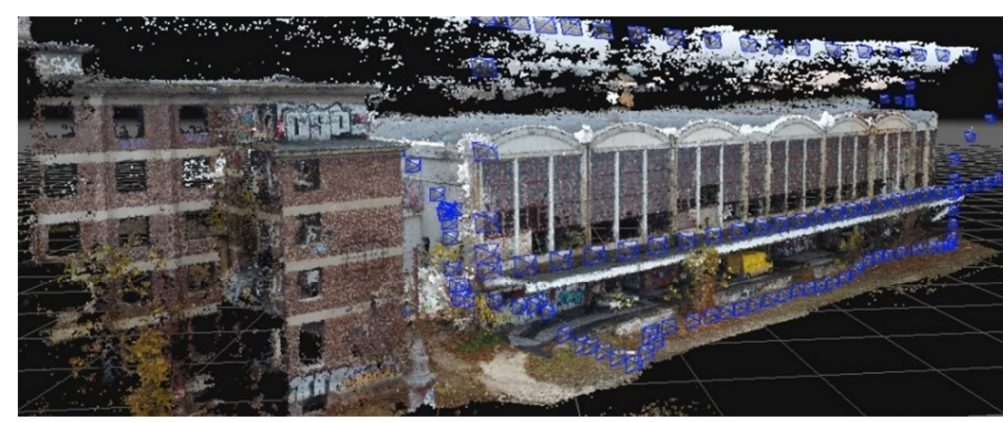

Fig. 6. The exterior photogrammetry surveying with saved camera positions (Source: Olivér Rák)
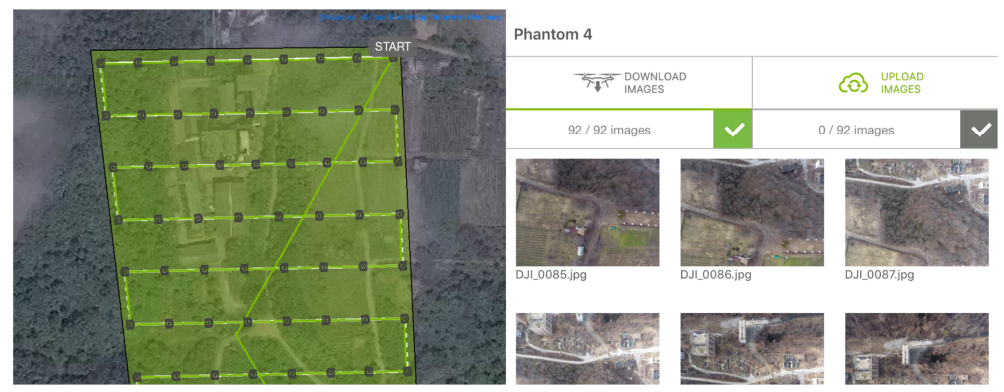

Fig. 7. Screenshot of the planned and completed flight by Litchi (Source: Olivér Rák)

The point cloud needs to be cleaned to get the shape of the ground. It was made a semi-automatic way with CloudCompare, which uses a filtering method for 'ground detection' [19]. Fig. 8 represents the cleaned terrain, where the vegetation height was decreased to define the ground level.

The purpose was to have a terrain model, which can be used in Graphisoft Archicad 21. For that, a lot of optimization was required to reach the usable form. As it is shown in Fig. 9 two different levels of detailed mesh is produced, which were created in PhotoScan and imported into the modeler software.

During the designing process, it can be used as a combined surface with point cloud and imported mesh. In this case, the strength of the software and computer has to be taken into account because the modeler software is not optimized well for managing more than a million points and a million polygons.

Table I represents the surveying methods in numbers. There are significant differences but those are coming from different software settings. For instance, the generated point's number is much higher in the case of the family house than the landscape. It is coming from different fields of measuring and dense cloud optimization properties. In the case of the landscape, the high detailed surveying was not a 
requirement because only the terrain levels were important to determine, nevertheless, at the family house, the small building elements should be captured also.

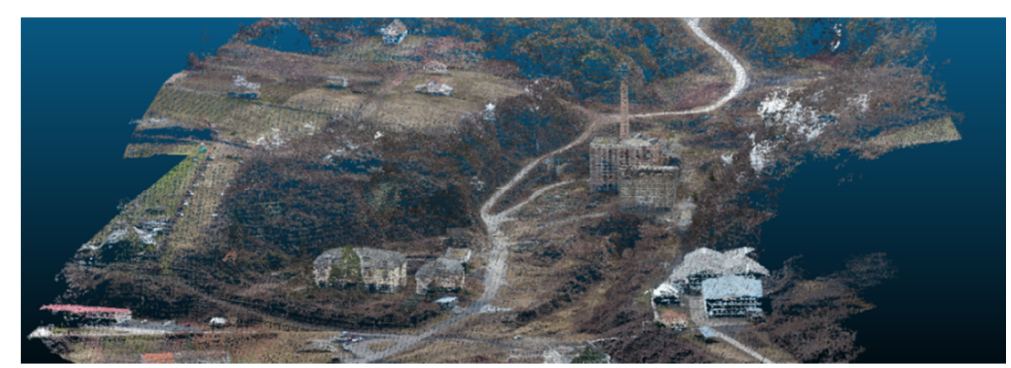

Fig. 8. Generated point cloud of the surveyed terrain (Source: Olivér Rák)

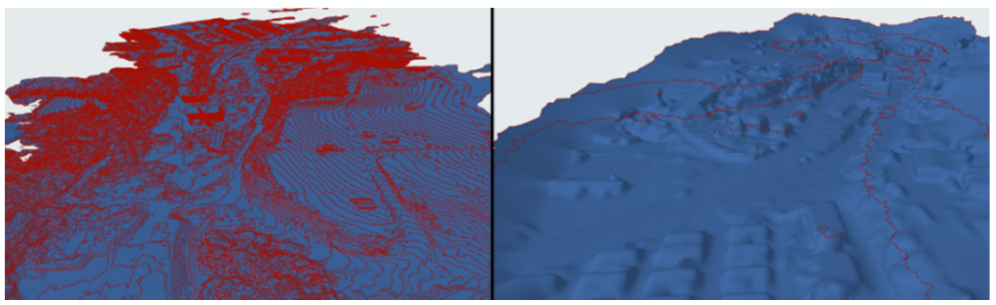

Fig. 9. The high and the low detailed mesh model (Source: Olivér Rák)

Table I

Summarized information and data quantity of the case studies

\begin{tabular}{|l|c|c|c|c|}
\cline { 2 - 5 } \multicolumn{1}{c|}{} & Family house & Row house & Old market hall & Landscape \\
\hline Number of pictures & $89 \mathrm{pcs}$ & 35 (video: 61$) \mathrm{pcs}$ & $725 \mathrm{pcs}$ & $823 \mathrm{pcs}$ \\
\hline Surveying time & $15 \mathrm{~min}$. & $10 \mathrm{~min}$. & 3 hours & 4 hours \\
\hline Generated points & 48491830 & 10039465 & 10467782 & 30071415 \\
\hline
\end{tabular}

\section{Conclusion}

As a conclusion of this research it needs to be stated that the photogrammetry technology can be used in the field of architectural survey. The technology is developed enough for the exterior surveying but has some difficulties in the case of interior spaces, which comes from the light circumstances. Increasing the number of captured images can improve the efficiency and the accuracy of building surveying, but the software calculation time will increase also. There are differences in the software platforms and applications as well; however, testing these was not in the scope of the research. The accuracy of the result is depending on the image resolution and overlapping, software algorithms, lights, reference points and captured extra data (GPS, lens, etc...) related the photos. 
The technology does not need a high experience of the surveying only have to know the rules which are mentioned in point 2.1. If special cases or more accurate results are the requirements, a specialist is necessary to involve in the project because of the countless options during the photo shooting and the AP too. This paper presents a few case studies, which are representing the different fields of architectural usage. All of those can be managed by this technique, but for the good results, a UAV is needed to have because some of the details cannot be reached by the hand-held camera an account of photographer position.

After the surveying process if the requirement is to build a 3D model of the existing phase the software performance needs to be tested. Most of those have problems to manage point clouds but the continuous IT developments will solve the issues.

In the future research scope, a more detailed and specified technical report will be developed because this knowledge is essential for professionals to be able to use this modern technology to improve their knowledge and company efficiency.

\section{Acknowledgments}

The research and the article were financed and supported by 'Ministry of Human Capacities, Human Resource Support Manager' with the identification 'NTP-NFTÖ18', entitled 'National Young Talent Scholarship', and by the PTE MIK BIM Research Group.

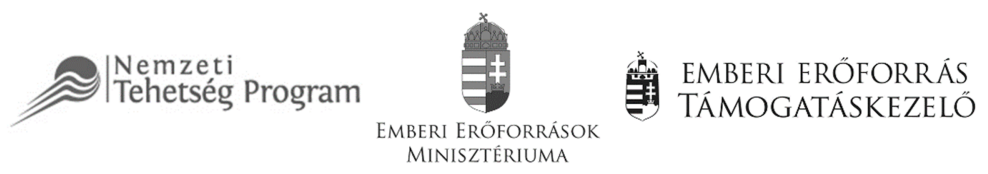

\section{Open Access statement}

This is an open-access article distributed under the terms of the Creative Commons Attribution 4.0 International License (https://creativecommons.org/licenses/by/4.0/), which permits unrestricted use, distribution, and reproduction in any medium, provided the original author and source are credited, a link to the CC License is provided, and changes - if any - are indicated. (SID_1)

\section{References}

[1] Berényi A. Laser scanning in engineering survey, Pollack Periodica, Vol. 5, No. 2, 2010, pp. 39-48.

[2] Packale'n P., Maltamo M. Predicting the plot volume by tree species using airborne laser, Forest Science, Vol. 52, No. 6, 2006, pp. 611-622.

[3] Filippelli S. K., Lefsky M. A., Rocca M. E. Comparison and integration of lidar and photogrammetric point clouds for mapping pre-fire forest structure, Remote Sensing of Environment, ol. 224, 2019, pp. 154-166. 
[4] O'Driscoll J. Landscape applications of photogrammetry using unmanned aerial vehicles, Journal of Archaeological Science: Reports, Vol. 22, 2018, pp. 32-44.

[5] Ferrabya R., Powlesland D. Heritage and landscape change: Recording, archiving and engaging, Proceedings of the Geologists' Association, 2019.

[6] Kenarsari A. E., Vitton S. J., Beard J. E. Creating 3D models of tractor tire footprints using close-range digital photogrammetry, Journal of Terramechanics, Vol. 74, 2017, pp. 1-11.

[7] Smith M. W., Vericat D. From experimental plots to experimental landscapes: topography, erosion and deposition in sub-humid badlands from structure-from-motion photogrammetry, Earth Surface Processes and Landforms, Vol. 40, No. 12, 2015, pp. $1656-1671$.

[8] Cunliffe A. M., Brazier R. E., Anderson K. Ultra-fine grain landscape-scale quantification of dryland vegetation structure with drone-acquired structure-from-motion photogrammetry, Remote Sensing of Environment, Vol. 183, 2016, pp. 129-143.

[9] Chen J., Dowman I., Li S., Li Z., Madden M., Mills J., Paparoditis N., Rottensteiner F., Sester M., Toth C., Trinder J., Heipke C. Information from imagery: ISPRS scientific vision and research agenda, ISPRS Journal of Photogrammetry and Remote Sensing, Vol. 115. 2016, pp. 3-21.

[10] Somogy Á., Lovas T. Barsi Á. Comparision of spatial recosntruction software package using DSLR images, Pollack Periodica, Vol. 12, No. 2, 2017, pp. 17-27.

[11] Lu E., Zhao Z., Wang Q., Liu Y., Liu L. A weighting intersection point prediction iteration optimization algorithm used in photogrammetry for port hoisting machinery, Optics and Laser Technology, Vol. 111, 2019, pp. 323-330.

[12] Aicardi I., Chiabrando F., Lingua A. M., Noardo F. Recent trends in cultural heritage 3D survey: The photogrammetric computer vision approach, Journal of Cultural Heritage, Vol. 32, 2018, pp. 257-266.

[13] Agisoft PhotoScan user mannual, version 1.4, 2018, https://www.agisoft.com/pdf/ photoscan-pro_1_4_en.pdf, (last visited 15 April 2019).

[14] 3Dflow srl., 3DFLOW 3DF Zephyr, http://3dflow.net/zephyrdoc/3DF\%20Zephyr\%20Manual\%204.300\%20English.pdf, (last visited 15 April 2019).

[15] Coded targets and scale bars in Agisoft PhotoScan Pro 1.0.0, https://www.agisoft.com/pdf/ PS 1.0.0 Tutorial\%20(IL)\%20-\%20Coded\%20Targes\%20and\%20Scale\%20Bars.pdf, (last visited 15 April 2019).

[16] Légtér.hu Ltd, https://legter.hu/en/, (last visited 15 April 2019).

[17] Phantom-4, DJI Technology Co, Ltd, https://www.dji.com/hu/phantom-4 (last visited 15 April 2019).

[18] Apple Inc, One Apple park way, Cupertino, CA 95014, USA, https://www.apple.com/ipad9.7/specs/, (last visited 15 April 2019).

[19] Zhang W., Qi J., Wan P., Wang H., Xie D., Wang X.,Yan G. An easy-to-use airborne LiDAR data filtering method based on cloth simulation, Remote Sensing, Vol. 8, No. 6, 2016 , pages 22 . 